\title{
A Perspective of Preconception Health Activities in the United States
}

\author{
Sheree L. Boulet • Kay Johnson • Christopher Parker • \\ Samuel F. Posner • Hani Atrash
}

Published online: 8 June 2006

(C) Springer Science+Business Media, Inc. 2006

\begin{abstract}
Objectives: Information regarding the type and scope of preconception care programs in the United States is scant. We evaluated State Title V measurement and indicator data and abstracts presented at the National Summit on Preconception Care (June 2005) in order to identify existing programs and innovative strategies for preconception health promotion.

Methods: We used the web-based Title V Information System to identify state Performance Measures and Priority Needs pertaining to preconception health as reported for the 2005-2010 Needs Assessment Cycle. We also present a detailed summary of the abstracts presented at the National Summit on Preconception Care.

Results: A total of 23 states reported a Priority Need that focused on preconception health and health care. Forty-two states and jurisdictions identified a Performance Measure associated with preconception health or a related indicator (e.g., folic acid, birth spacing, family planning, unintended pregnancy, and healthy weight). Nearly 60 abstracts pertaining to preconception care were presented at the National Summit and included topics such as research, programs, pa-
\end{abstract}

S. L. Boulet $(\triangle) \cdot$ C. Parker $\cdot$ H. Atrash

National Center on Birth Defects and Developmental Disabilities,

Centers for Disease Control and Prevention,

1600 Clifton Road, MS-E87, Atlanta, GA 30333, USA

e-mail: sboulet@cdc.gov

\section{K. Johnson}

Department of Pediatrics, Dartmouth Medical School,

Hanover, NH, USA

S. F. Posner

Division of Reproductive Health, Centers for Disease Control and

Prevention,

Atlanta, GA, USA tient or provider toolkits, clinical practice strategies, and public policy.

Conclusions: Strategies for improving preconception health have been incorporated into numerous programs throughout the United States. Widespread recognition of the benefits of preconception health promotion is evidenced by the number of states identifying related indicators.

Keywords Preconception care $\cdot$ Reproductive health · Pregnancy

\section{Introduction}

The June 2005 National Summit on Preconception Care, sponsored by the Centers for Disease Control and Prevention (CDC) and the March of Dimes, assembled an array of health care providers, public health practitioners, and researchers in an effort to promote the exchange of information and ideas related to preconception care at the local, state, and national levels. A key issue emerging from conference discussions was the perceived lack of information pertaining to the nature and scope of preconception health services currently being provided in the United States, whether explicitly defined or falling under another umbrella of services. Another issue was the recognition that a compilation of local, state, and national resources would provide important information related to the ability of current public health systems to address preconception care needs, as well as allow for the description of innovative models for the delivery of such services.

Attended by more than 400 registered participants representing a myriad of agencies and organizations, the summit generated significant response within the public health and clinical communities and reflects a perspective that cannot 
be readily gleaned from literature reviews or the inspection of existing programmatic guidelines: that is, the topic of preconception health has garnered substantial interest and support and has already been incorporated into numerous existing programs, policies, and strategies in the United States. Unique to the summit was an opportunity to learn about the development and administration of preconception care programs within clinical and population-based settings as Medline, PubMed, and other Internet searches have revealed very little information regarding the development and implementation of preconception care programs within a local context. However, as evidenced by the numerous programmatic components featured in the conference abstracts, such programs are being introduced in many different formats, among various private and public organizations, and across the entire nation.

Although little is now known at this writing about the scope and extent of U.S. programs and projects to promote preconception health, this article uses readily available sources (in the published professional literature and the gray literature of government and organization reports) to provide a snapshot of related activities in the United States. Thus, we are able to report the findings of a scan of State Title V Performance Measures and Priority Needs pertaining to preconception care and a detailed summary of the abstracts of the papers presented at the Summit.

\section{Methods}

The Maternal and Child Health Bureau website (http://mchb.hrsa.gov/) was used to ascertain the proportion of states including preconception health indicators in State Performance Measures and Priority Needs, as reported in the State Title V Maternal and Child Health Service (MCH) Block Grant FY 2004 Annual Report and FY 2006 Application, Form 14. The web-based Title V Information System (https://perfdata.hrsa.gov/mchb/mchreports/Search/core/ measureindicatemenu.asp) was used to search State Title V Performance Measures and Priority Needs for indicators related to preconception health. Initial search parameters included all keywords and all populations and were further refined by selecting for birth outcomes, reproductive health, and women. Those indicators for which infants, newborns, children, men, or service providers represented the sole target population were excluded. The remaining measures were evaluated based on their relevancy to preconception health. Indicators using the term "preconception" or "preconceptual" and those that did not use such terminology but adequately captured the concept were considered to fall within the domain of preconception health and health care. States identifying preconception health Priority Needs were depicted on a national map. States reporting relevant Per- formance Measures were identified and selected measures were described in tabular format. Finally, a comprehensive list of State Title V Performance Measures and Priority Needs related to preconception health, that reflected the tone and language of multiple states was developed.

All abstracts submitted and accepted for presentation at the National Summit on Preconception Care (June 2005) were pooled and subjectively categorized into five broad topic areas: research pertaining to preconception risk assessment and outcome evaluation; preconception care programs and activities; tools intended for provider or patient preconception health education; clinical practice strategies; and public policy related to preconception care.

\section{Results}

\section{State Title V Performance Measures and Priority Needs}

The federal MCH Block Grant guidance requires states to report annually on National "Core" Performance Measures and to assess needs and set priorities every 5 years. In addition, each state must develop 7 to 10 additional Performance Measures relevant to its own priority needs and programs. Priority Needs reflect a state's focus for programmatic efforts throughout the next five years and can be adjusted during interim years in response to variations in needs. Performance Measures describe a specific maternal and child need that, when effectively addressed, can lead to improvements in health. In 2005, states completed the 5-year needs assessments and set out priorities and targets for 2010. A previous analysis of the 2000 priorities and measures found that some states, but not all, included measures for preconception care or visits, as did Healthy People 2000 National Health Promotion and Disease Prevention Objectives [1].

Twenty-three states reported a Priority Need that focused on preconception health and health care (Fig. 1). "Preconception" or "preconceptual" health was mentioned by 10 states as a Priority Need in maternal and child health. In other states, Priority Needs indirectly addressed preconception care via broad objectives such as improving the health of women of childbearing age, promoting reproductive health and sexual responsibility, and advancing a holistic care continuum for women's health.

A total of 42 states and jurisdictions reported at least one Performance Measure related to preconception care, neural tube defects, birth spacing, family planning, unintended pregnancy, and healthy weight/obesity (Table 1). Unintended pregnancy and healthy weight or obesity were the measures identified most frequently ( $43 \%$ and $19 \%$, respectively). The majority of the measures pertaining to birth spacing or parity, or both, addressed repeat pregnancies among adolescent populations. A total of thirty states or territories reported 
Fig. 1 State Title V priority needs focused on preconception health and health care, U.S. 2005

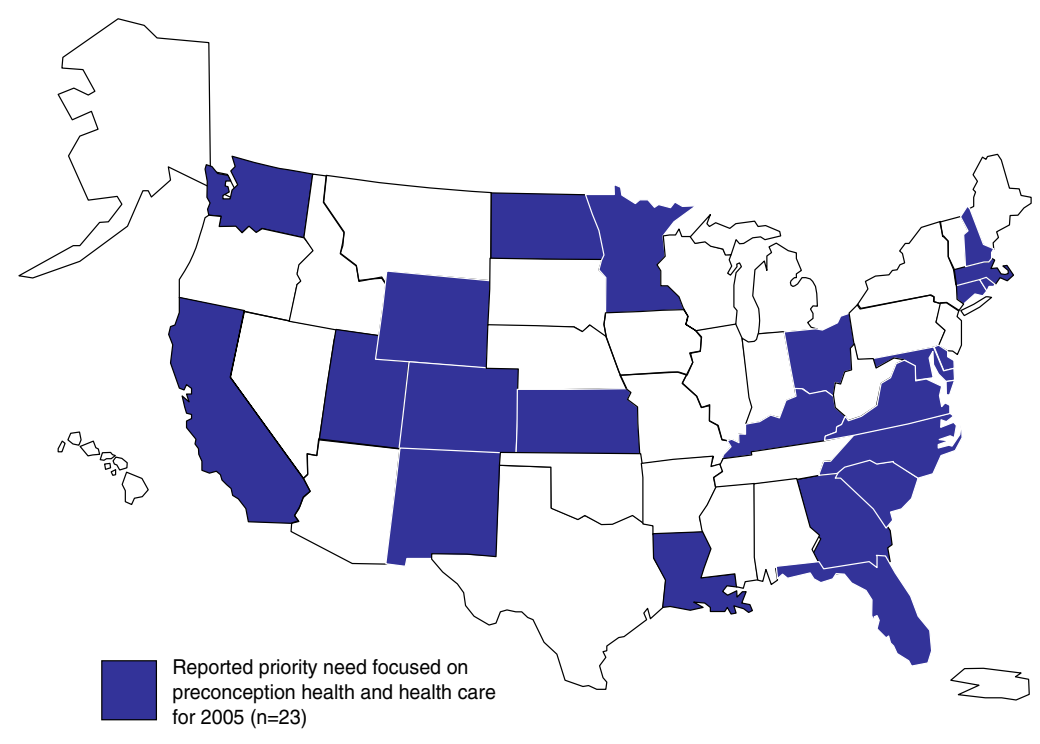

Source: Title V Information System <https://perfdata.hrsa.gov/mchb/mchreports/Search/core/measureindicate menu.asp>

measures on tobacco use during pregnancy; however, only one focused on the proportion of women who smoked during 3 months prior to pregnancy. Measures pertaining to smoking rates among women of childbearing age were reported by two states. Four states addressed mental health among women of childbearing age and postpartum depression was identified in three others. Two states included measures pertaining to preventive oral health services among women of childbearing age (data not shown).

Table 2 provides examples of selected State Performance Measures and Priority Needs derived from 18 states. Variations in state-selected preconception health indicators are evident, with some states detailing various components of preconception care and others employing a broader focus on reproductive health.

Abstracts from the National Summit on Preconception Care

A total of 59 abstracts accepted for presentation at the $\mathrm{Na}$ tional Summit on Preconception Care were reviewed and categorized according to primary area of focus. Approximately $32 \%$ addressed preconception health research; $27 \%$ described preconception care programs and activities; $22 \%$ outlined tools for provider or patient education; $15 \%$ detailed clinical practice strategies; and 3\% highlighted policy-based strategies for increasing access to preconception care services.

Among the research abstracts, the topics noted most frequently pertained to methods for preconception risk assessment, potential predictors of adverse pregnancy outcomes, and variations in preconception health indicators across high- risk populations. Three abstracts described the use of the Perinatal Periods of Risk (PPOR) model [2] for assessing risks among various populations. Other issues included folic acid awareness among women and health care providers, maternal nutrition, pregnancy planning and risk behaviors, preconception hepatitis $\mathrm{B}$ prevention, and workplace hazards.

The PPOR model facilitates the identification of four contributors to infant mortality: maternal health and prematurity, maternal care, newborn care, and infant health. Excess rates of fetal and infant mortality in any of the four components indicate a need for targeted interventions within that construct [2-4]. CityMatCH's 2000-2002 PPOR Practice Collaborative provided public health workers in 14 U.S. cities with the skills, knowledge, and support to implement the PPOR method in various urban communities [2]. The PPOR approach is also is being used statewide by Florida and Ohio and in selected areas across the country [2-4].

The Fountain Project in Kansas City, Missouri linked PPOR techniques with the Fetal Infant Mortality Review (FIMR) process in an effort to identify the causes of consistently higher rates of infant mortality among AfricanAmerican residents compared with their non-Hispanic White counterparts. The findings of the analysis indicated an excess rate of maternal health or prematurity-related deaths among African-American infants. In light of the contributing social factors identified by the FIMR, the development of a Women's and Children's Wellness Center was proposed to provide social and clinical services for high-risk families (Cook BE, Guillory VJ, Cai J, Hoff GL, Manning J, unpublished data, 2005). 
Table 1 States or U.S. jurisdictions reporting Performance Measures related to selected preconception health topics

\begin{tabular}{|c|c|c|c|c|c|c|}
\hline \multirow[b]{2}{*}{ State } & \multicolumn{6}{|c|}{ Performance Measure } \\
\hline & $\begin{array}{l}\text { Preconception } \\
\text { care }\end{array}$ & $\begin{array}{l}\text { Neural tube } \\
\text { defects/folic } \\
\text { acid }\end{array}$ & $\begin{array}{l}\text { Birth } \\
\text { spacing/parity }\end{array}$ & Family planning & $\begin{array}{l}\text { Unintended } \\
\text { pregnancy }\end{array}$ & $\begin{array}{l}\text { Healthy } \\
\text { weight/obesity }\end{array}$ \\
\hline Arizona & & & & $x$ & & \\
\hline Arkansas & & & & & & $x$ \\
\hline California & & $\times$ & & & & \\
\hline Delaware & & & $x$ & & & \\
\hline District of Columbia & & & $x^{a}$ & & $x$ & \\
\hline Florida & & & $x^{a}$ & & & \\
\hline Georgia & & $\times$ & $x^{a}$ & & & \\
\hline Guam & & & & & $\times$ & \\
\hline Hawaii & & & & & $x$ & \\
\hline Illinois & & & & & $x$ & \\
\hline Indiana & & & $\times$ & & & \\
\hline Kentucky & $x$ & & & & & \\
\hline Louisiana & & & & $x$ & & \\
\hline Maine & & & & & $x$ & \\
\hline Marshall Islands & & & & $x^{b}$ & & \\
\hline Maryland & & & & & $x$ & \\
\hline Massachusetts & & & $x$ & & $\times$ & \\
\hline Michigan & & & & & $x$ & \\
\hline Minnesota & & & & & $x$ & \\
\hline Mississippi & & & $x^{a}$ & & & \\
\hline Montana & & & & & $\times$ & \\
\hline Nebraska & & & & & & $x$ \\
\hline Nevada & & & & & & $x$ \\
\hline New Jersey & & & $x^{a}$ & & & \\
\hline New Mexico & $x$ & & & & $x$ & \\
\hline New York & & & & & $x$ & \\
\hline North Carolina & & $\times$ & & & $x$ & $x$ \\
\hline North Dakota & & & & & & $x$ \\
\hline Northern Mariana Islands & & & & & $\times$ & \\
\hline Ohio & & & & & $\times$ & \\
\hline Oklahoma & & & & & $\times$ & \\
\hline Puerto Rico & & $x$ & & & & \\
\hline South Carolina & & & & & $x$ & \\
\hline Tennessee & & & & & & \\
\hline Texas & & & & & & $x$ \\
\hline South Dakota & & & & & $x$ & \\
\hline Wyoming & & $x^{c}$ & & & & \\
\hline Utah & & & & & & $x$ \\
\hline Vermont & & & & & & $x$ \\
\hline Washington & & & & $x^{b}$ & & \\
\hline Wisconsin & & & & $x$ & & \\
\hline
\end{tabular}

${ }^{a}$ Measure references repeat births/pregnancies among adolescents only.

${ }^{b}$ Measure references family planning counseling or postpartum birth control planning as addressed during routine prenatal care.

${ }^{\mathrm{c}}$ Measure references multivitamin use in month prior to conception.

In an effort to facilitate the analysis of various perinatal health outcomes, a group of nine counties surrounding the San Francisco Bay (California) formed the Maternal, Child and Adolescent Health Bay Area Data Collaborative (BADC). The group used the PPOR model to evaluate recent county and regional fetal-infant mortality rates and reported substantial excess in the proportion of deaths among African-American infants, particularly in the prematurity and maternal health component of the model. Using a national comparison group, these investigators were able to determine that approximately $56 \%$ of the excess deaths among African-American infants could be prevented by 
Table 2 Sample of selected state Performance Measures and Priority Needs related to preconception health

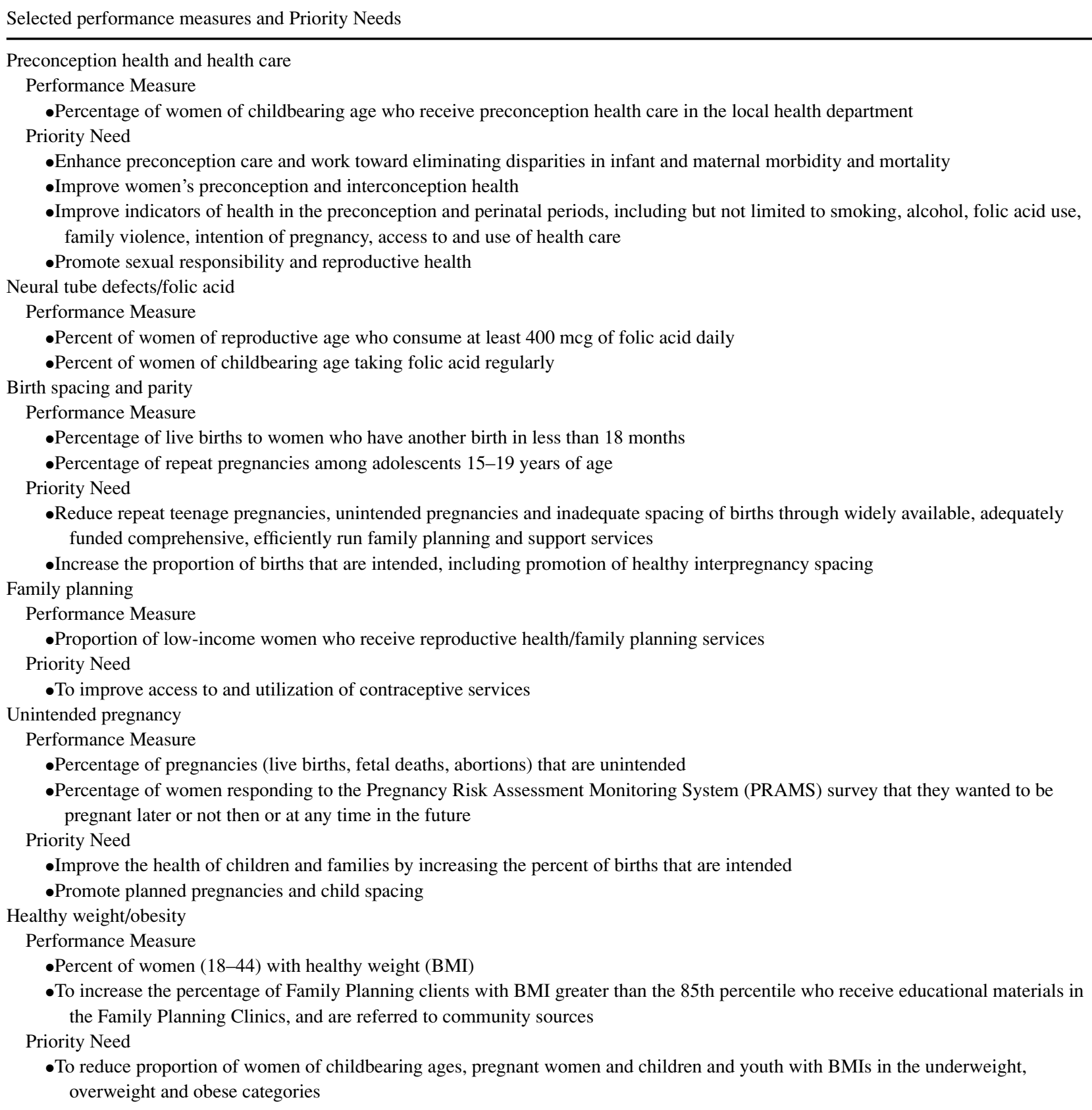

targeting preconception and interconception risk factors (Stein EJ, Abramowitz A, Brown J, Chabra A, unpublished data, 2005).

Federally funded Healthy Start projects were highly represented among the 16 abstracts detailing preconception care programs and activities presented at the Summit. Of these, seven abstracts described the modification or expansion of existing programs to include direct services or communitybased interventions for high-risk postpartum mothers or all women of reproductive age. The Magnolia Project in
Jacksonville, Florida is an example of a Healthy Start program in which a comprehensive array of health services was offered in an effort to improve birth outcomes. Services included, but were not limited to, case management, education and risk reduction, and well-woman care. The target population was high-risk African-American women aged 15-44 years who lived in five zip code areas of Jacksonville. The project operates as a collaborative between the Northeast Florida Healthy Start Coalition, the Duval County Health Department, and local community-based organizations. As 
reported, a 2004 assessment of project services conducted by the Health Resources and Services Administration (HRSA) Office of Performance Review found high rates of success $(>70 \%)$ in the resolution of key risks (for example, lack of family planning, and rates of repeat sexually transmitted diseases) among the project participants (Brady, CM, unpublished data, 2005).

The Missouri Bootheel Healthy Start project, a provider of referral and education services in a five county area of southeast Missouri, uses community-based education and interventions to improve adverse perinatal outcomes. The project has been one of few in the area that has promoted a family-focused approach to health education through the inclusion of various services directed at men. The curriculum for fathers has addressed a variety of issues, such as communication with the mother, addressing stress in the relationship, and the impact of nutrition on birth outcomes (Dean CG, Campbell T, Frazier V, Washington J, unpublished data, 2005).

Title $\mathrm{X}$ family planning clinics were identified as providers of preconception primary care and folic acid awareness interventions in two programs and activities abstracts. The Women Enjoying Life Longer (WELL) Project was initiated by the Maryland Department of Health and Mental Hygiene following a community needs assessment. Comprehensive preventive women's health services were added to three Title $\mathrm{X}$ family planning clinics in Baltimore County, using Title X and Maternal and Child Health funding. Augmented services included nutrition and physical activity counseling, adult immunizations, smoking cessation interventions, and preconception counseling, as well as referrals for problems such as substance abuse, depression, domestic violence, and chronic disease. Early evaluation data indicated that patients and staff have responded positively to new services, patient knowledge of women's health has improved, and patient volume has increased 37\% (Cheng D, unpublished data, 2005).

The Oklahoma Birth Defects Registry developed, implemented, and evaluated a preconception "women's health appraisal" project. The intervention was comprised of a 3-page health appraisal for women, with follow-up risk counseling, in selected family planning clinics (two rural and one urban). Pre-evaluation results indicated that $84 \%$ of nurses found the questionnaire helpful in assessing risk factors, $90 \%$ of nurses found it helpful as a guide to counseling and referrals, and $86 \%$ of patients increased their understanding of risk factors. Post-evaluation results found that $62 \%$ of patients modified one to three risk factors in a three-month period (Feuerborn VR, Pearson K, unpublished data, 2005).

The remaining programs were funded either through grants, private organizations, or state/local health departments and comprised comprehensive health care programs for women with a history of preterm delivery or a low birth weight infant and broad women's wellness interventions aimed at improving women's health or folic acid utilization. For example, the Interpregnancy Care Program at Grady Memorial Hospital in Atlanta, Georgia employs a "resource mother" to coordinate the provision of primary health care and dental services, enhanced nurse case management, and other outreach services to African-American women who delivered a very low birth weight infant at the hospital and who qualified for indigent or charity care. For 24 months postpartum, the women were offered health care visits every 1-3 months in order to address risks known to be associated with the delivery of a low birth weight infant such as poorly controlled chronic disease, short intervals between pregnancies, reproductive tract infections, periodontal disease, nutritional deficits, substance abuse, and stress. Preliminary evaluation of the 22 women retained in the pilot program indicated that approximately one-quarter of them were affected by unrecognized or poorly managed chronic health problems and none of the participants wanted to become pregnant during the next 2 years (Dunlop A, unpublished data, 2005).

Thirteen abstracts (22\%) described the creation, dissemination, and evaluation of tools for patient or provider education. Of those, eight described marketing campaigns and toolkits for patient education, three specifically referenced provider education, and three assessed the use of women's health appraisals by health care providers. For example, the California Preconception Care Initiative, Every Woman, Every Time, was created in 1989 through a partnership between Sutter Medical Center in Sacramento and the March of Dimes. The project conducted a metanalysis of the preconception care literature [5] and used this information in a consensus development process to produce a marketing packet for providers. Key components of the packet included the rationale for providing preconception care, a description of the essential elements of care, patient education materials, and information on billing methods. More than 9,000 packets were distributed statewide. An evaluation found that, among 187 providers responding, $75 \%$ indicated the information was very useful, $80 \%$ said they would distribute materials to patients, and $72 \%$ said they would use the billing codes provided. A further impact evaluation is being considered (Cullum AS, unpublished data, 2005).

A research project conducted at a New York innercity hospital served by Albert Einstein College of Medicine/Montefiore Medical Center sought to evaluate the knowledge and awareness of providers regarding preconception care. A pre-intervention chart review and a provider survey were conducted to evaluate delivery or preconception care. The two-part intervention included: [1] a 1-h lecture for all providers, and [2] a standardized preconception care form inserted into all charts. A post-intervention chart review of a convenience sample and repeated provider survey were then conducted. The result was a significant improvement in 
documentation of the delivery of preconception care $(p<0.05)$; however, provider knowledge and attitudes, as measured by the survey, did not change significantly (Bernstein P, unpublished data, 2005).

Clinical practice strategies were discussed in nine abstracts and included topics such as genomics, group care, screening for environmental exposures and maternal depression, smoking cessation, and provider knowledge of current practice guidelines. An example of a promising practice strategy presented at the Summit is the use of a group model of prenatal care to address topics relevant to preconception care. In 2002, the Comprehensive Family Care Center at Montefiore Medical Center implemented the group model of prenatal care developed by the Centering Pregnancy and Parenting Association. Traditional prenatal visits were replaced with group appointments lasting approximately 2 hours and attended by 10 to12 women. Typical clinical care services were provided during the visits and were supplemented with group discussions on pregnancy-related topics. Issues related to preconception health were covered during many of the meetings and included nutrition, substance abuse, contraception, and family planning. Since its inception, the group care model has been employed for 14 patient groups with high levels of patient and provider satisfaction reported, particularly related to enhanced opportunities for patient education (Bernstein P, Rising SS, Dolan S, Pardanani S, Merkatz IR, unpublished data, 2005).

Finally, policy-based strategies for the funding of preconception care were described in a small number of abstracts. One pair of abstracts highlighted Illinois' efforts to promote preconception health using public policy and funding through Medicaid waivers, Title V, and other resources (Murphy AM, unpublished data, 2005; Saunders SE, unpublished data, 2005). Identified as a priority area, preconception care has been integrated into a number of programs, most notably the Illinois Healthy Women program. This Medicaid waiver program initiative extends coverage for family planning services to women who would otherwise lose their benefits after 60 days postpartum and to all women 19 through 44 years of age who were previously enrolled in Medicaid but who had lost their benefits (Murphy AM, unpublished data, 2005). Additional efforts have been made through the Illinois Family Planning Program. Preconception education is currently provided at all state-funded family planning clinics, with 16 state family planning agencies offering additional counseling and referral for high-risk clients [6]. Other strategies employed by the Illinois Department of Human Services include statewide genetic counseling programs and folic acid campaigns, screening mothers of children enrolled in the state's Medicaid program for perinatal depression, and programs aimed at increasing birth spacing and promoting the health of teen parents (Saunders SE, unpublished data, 2005).

\section{Conclusions}

In public health, effective programs are those developed in response to a well-defined problem analysis, are mindful of the local context, and apply proven interventions. Although the scientific evidence in support of some preconception interventions is relatively well described within the literature, topics discussed during the National Summit on Preconception Care reframed the issues in light of new findings regarding unmet needs, health disparities, service delivery models, and tools such as the PPOR to assess risks among populations. Variations in the type and scope of policies, programs, and strategies were evident both in the diversity of the summit abstracts and in the state Title $\mathrm{V}$ indicators. Clearly, a preconception focus is being woven into existing programs and guiding the development of new initiatives. Innovative strategies are being implemented that target a variety of populations including community groups, health care providers, medical students, adolescents, and fathers. Finally, many state indicators are adopting a broader language to encompass the health needs of women of childbearing age and support the notion of a lifespan approach to preconception health.

It should be noted that the findings reported in this brief are limited by a number of factors. First, state measures and priorities reported by the federal Maternal and Child Health Bureau might not reflect the programs and projects actually being implemented by states and communities; they are only an expression of interest and concern. Next, the content of the abstracts accepted for the National Summit on Preconception Care presented a selection of current research, policies, and programs and, therefore, does not fully represent the scope of national preconception care projects. Finally, the identification of preconception health state Title $\mathrm{V}$ indicators required a certain amount of subjective interpretation regarding the actual focus of the Priority Need or Performance Measure. Although the authors have considerable knowledge of the definition and content of preconception care, it is possible that certain indicators might have been incorrectly excluded or included due to misinterpretation.

Notwithstanding these limitations, the results of the present analysis indicate a widespread recognition of the need for a continuum of care that starts well before birth, involves both men and women, and employs a lifespan approach to emotional and physical well-being. Because preconception interventions can take place at any time during a woman's reproductive life and across a variety of dimensions, countless opportunities exist for positively influencing the health of women, children, and families. The variations among domestic preconception health projects and related public health priorities are reflective of the true breadth of the topic. If a national agenda for preconception health is to be moved forward, it is imperative that these efforts 
continue to be fostered and expanded in all settings and across a multitude of disciplines.

Acknowledgment This research was supported in part by an appointment to the Research Participation Program at the National Center on Birth Defects and Developmental Disabilities, Centers for Disease Control and Prevention, administered by the Oak Ridge Institute for Science and Education through an interagency agreement between the U.S. Department of Energy and CDC.

\section{References}

1. Johnson KA, Little GA. State health agencies and quality improvement in perinatal care. Pediatrics 1999;103(1 Suppl E):233-47.
2. CityMatCH.org [homepage on the Internet] Nebraska: CityMatCH and the Section on Child Health Policy. Perinatal Periods of Risk Approach in US cities. [cited 2005 Nov 16] Available from: http://citymatch.org/PPOR/.

3. Burns PG. Reducing infant mortality rates using the perinatal periods of risk model. Public Health Nurs 2005;22(1):2-7.

4. Cai J, Hoff GL, Dew PC, Guillory VJ, Manning J. Perinatal periods of risk: analysis of fetal-infant mortality rates in Kansas City, Missouri. Matern Child Health J 2005;9(2):199-205.

5. Korenbrot CC, Steinberg A, Bender C, Newberry S. Preconception care: a systematic review. Matern Child Health J 2002;6(2):7588.

6. Gold RB. Providing basic genetic services: what role for family planning clinics? The Guttmacher Report on Public Policy 2005;8(4):4 5 . 